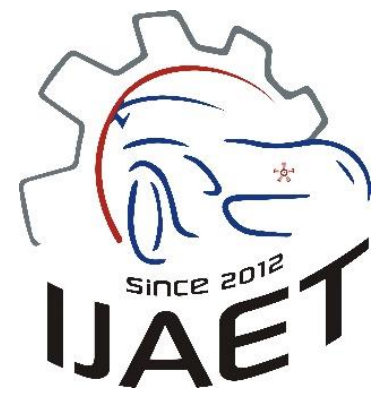

e-ISSN: 2146 - 9067

International Journal of Automotive

Engineering and Technologies

journal homepage:

https://dergipark.org.tr/en/pub/ijaet

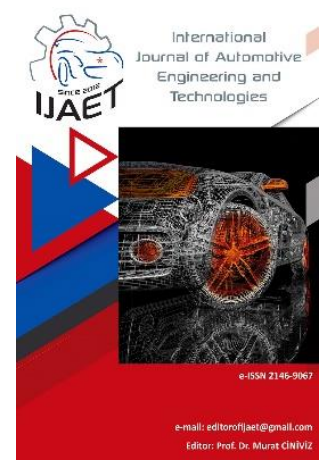

Original Research Article

\title{
Investigation of engine performance and emission parameters of a diesel engine fueled with Foeniculum vulgare oil biodiesel - ammonia mixtures
}

\author{
Ömer Böyükdipi ${ }^{1, *}$, Gökhan Tüccar ${ }^{2}$
}

${ }^{1,2}$ Adana Alparslan Türkeş Science and Technology University, Department of Mechanical Engineering, 01250 Adana, Turkey

\section{ARTICLE INFO}

Orcid Numbers

1. 0000-0002-6205-5440

2. 0000-0003-3041-299X

Doi: $10.1824 /$ ijaet. 832525

* Corresponding author

o.boyukdipi@gmail.com

Received: Dec 03, 2020

Accepted: Oct 14, 2021

Published: 09 Nov 2021

Published by Editorial Board Members of IJAET

(C) This article is distributed by Turk Journal Park System under the CC 4.0 terms and conditions. \begin{abstract}
Past studies revealed that Foeniculum vulgare oil biodiesel (FVB) can be used as a good candidate for diesel fuels. Ammonia $\left(\mathrm{NH}_{3}\right)$ as a fuel additive can be mixed with other fuels to eliminate some disadvantages of the fuels in engine performance and emission. In view of such information, this study aims to investigate the effects of FVB with $\mathrm{NH}_{3}$ additive on engine performance and emission parameters in Diesel-RK Programme. In this study, FVB was mixed with $\mathrm{NH}_{3}$ additive in different proportions (FVB100, FVB95A5, FVB90A10, FVB85A15 and FVB80A20). The exhaust emissions (Oxides of Nitrogen $\left(\mathrm{NO}_{\mathrm{x}}\right.$ ), Particulate Matter (PM) and Smoke Opacity) and engine performance (Specific Fuel Consumption (SFC), Power, Torque and Volumetric Efficiency) parameters were evaluated according to the combustion simulations in different RPM values. As a result of this study, some obtained results were revealed that the $\mathrm{NH}_{3}$ additive in FVB significantly decreased the $\mathrm{NO}_{x}$ parameter. However, when the $\mathrm{NH}_{3}$ content in FVB was increased, PM and smoke opacity parameters increased. For the engine performance parameters, the $\mathrm{NH}_{3}$ additive in $\mathrm{FVB}$ adversely affected the engine power and torque parameters. On the other hand, specific fuel consumption and volumetric efficiency showed an increment trend as the $\mathrm{NH}_{3}$ content in FVB was increased.

Keywords: Foeniculum vulgare oil biodiesel, Ammonia additive, Exhaust emission, Engine performance, Diesel-RK
\end{abstract}

\section{Introduction}

The world's energy needs dramatically increase every year due to the increase in the human population and industrialization. In 2020, the world's energy need has been expected to increase to $180,000 \mathrm{GWh} /$ year because of the predictable reasons [1]. The dependence on petroleum-derived fuels increased to meet this energy demand. Therefore, a lot of studies were performed to reduce this dependency. Biodiesel and various fuel additives were investigated to enhance engine performance and emission due to the high usage of petroleum fuels by many researchers. In the scope of this study, $\mathrm{NH}_{3}$ $\left(\mathrm{NH}_{3}\right)$ is aimed to use as a fuel additive to eliminate the negative effects of petroleum derived fuels and energy demand as mentioned in the previous section. $\mathrm{NH}_{3}$ does not contain a carbon atom. Therefore, the usage of $\mathrm{NH}_{3}$ as a fuel additive has many advantages about the decreasing of emission parameters. In line with these studies, various fuels with $\mathrm{NH}_{3}$ additive 
come to the fore due to having better chemical properties in the aim of decreasing the effects of emission gases according to other fuel additives. On the other hand, $\mathrm{NH}_{3}$ has a wide range of uses such as agricultural, chemical and other sectors. At the same time, $\mathrm{NH}_{3}$ is used as the main constituent in the production of fertilizers and a lot of chemicals. When the chemical properties of $\mathrm{NH}_{3}$ and its usage areas in the energy sector are examined, it can be evaluated as the green fuel of the future. Several studies have been done about the use of $\mathrm{NH}_{3}$ as an additive to different types of fuel. R. Sivasubramanian et al. [2] investigated the effects of the mustard methyl ester with $\mathrm{NH}_{3}$ additive on the emissions parameters of compression ignition engines. A significant reduction was obtained in emission parameters as a result of this study. Şahin et al. [3] experimentally analyzed the engine performance and exhaust emissions parameters by using the $\mathrm{NH}_{3}$ fumigation method in a small engine. The obtained results showed that $\mathrm{NH}_{3}$ has a great potential for using as a fuel additive in diesel engines. Ryu et al. [4] investigated the effects of $\left(\mathrm{NH}_{3}\right)$ and dimethyl ether (DME) mixtures on the combustion and emissions parameters in a compression-ignition engine. The obtained results revealed that the high content of $\mathrm{NH}_{3}$ can be used in a DI diesel engine using the appropriate injection system. On the other hand, it was found that the exhaust control system is required for reducing emission parameters. Reiter et al. [5] investigated the effects of $\mathrm{NH}_{3}$-diesel fuel mixtures on the combustion and emissions parameters in the compression-ignition engine. The obtained results showed that if the amount of $\mathrm{NH}_{3}$ in the diesel fuel does not exceed $60 \%$, a significant reduction can be obtained in the $\mathrm{NO}_{\mathrm{x}}$ emission parameter. The lower flame temperature and the amount of $\mathrm{NH}_{3}$ can cause the reduction of $\mathrm{NOx}$ emission parameter in the compression-ignition engine. Ryu et al. [6] developed a direct injection system for using gaseous $\mathrm{NH}_{3}$ in a spark-ignition engine and investigated the effects of $\mathrm{NH}_{3}$-gasoline mixtures on the engine performance and emission parameters. The obtained results showed that the $\mathrm{NH}_{3}$ additive decreased the brake specific carbon monoxide (BSCO) for all combinations. On the other hand, the $\mathrm{NH}_{3}$ additive dramatically increased brake specific hydrocarbon (BSHC) due to the reduction of $\mathrm{NH}_{3}$ combustion temperature and the $\mathrm{NH}_{3}$ additive caused the increment of oxides of nitrogen $\left(\mathrm{NO}_{\mathrm{x}}\right)$ emissions parameter in this study. Gross et al. [7] investigated the effects of $\mathrm{NH}_{3}$-dimethyl ether (DME) mixtures combinations on the combustion and emission parameters in a compression- ignition engine. The obtained results revealed that when the $\mathrm{NH}_{3}$ was added to DME fuel, the combustion pressure and temperature decreased in compression ignition engine. Therefore, carbon monoxide (CO) and hydrocarbon (HC) emission parameters showed a certain increment but on the other hand, soot emission remained so low according to other emission parameters. Yeh et al. [8] compared $\mathrm{NH}_{3}$ with monoethanolamine (MEA) solvents to observe the effects on carbon dioxide $\left(\mathrm{CO}_{2}\right)$ greenhouse gas emissions. They revealed that $\mathrm{NH}_{3}$ is a more effective solvent in absorbing and removing $\mathrm{CO}_{2}$ according to MEA solvents. Rehbein et al. [9] mixed $\mathrm{NH}_{3}$ with organic solvents and revealed that it's being potential alternative fuel for internal combustion engines. They concluded that $10 \%$ wt $\mathrm{NH}_{3}$ in methanol is a suitable mixture ratio due to having lower $\mathrm{CO}_{2}$ emission. Pyrc et al. [10] investigated experimentally the effects of diesel- $\mathrm{NH}_{3}$ solution $\left(\mathrm{NH}_{4} \mathrm{OH}\right)$ on performance, emission and combustion stability by using compression ignition engine. They revealed that the advantages of $\mathrm{NH}_{3}$ as a fuel against harmful emission gases.

The Foeniculum vulgare (Apiaceae) commonly is known as fennel and has a wide range of uses. In addition to that fennel is often used in medical treatments. Because F. Vulgare has essential curing properties for 43 different kinds of diseases. Therefore, it is used among most of the countries throughout the world. These countries are Bolivia, Brazil, Ecuador, Ethiopia, India, Iran, Italy, Jordan, Mexico, Pakistan, Portugal, Serbia, South Africa, Spain, Turkey, and the USA [11]. The essential oil of fennel can be used as an antioxidant, antifungal and antibacterial. Therefore, it has wide areas of usage [12]. The essential oil can be produced from the plant. On the other hand, seeds have contained $90 \%$ of the essential oil [13]. DieselRK Programme is a commercial simulation software that computes and optimizes the combustion, engine performance and emission parameters. There are several studies that 
investigate these parameters by using the Diesel-RK Programme. Al-Dawody et. al [14] investigated that the combustion, performance and emission parameters of soybean biodiesel diesel mixtures by using Diesel-RK Programme. Datta et. al [15] investigated that the engine emission and performance parameters of dieselbiodiesel-methanol mixtures by using the Diesel-RK Programme.

This study aims to analyze the effects of FVB with $\mathrm{NH}_{3}$ additive on engine performance and emission parameters by using Diesel-RK Programme. In the literature, there are several studies that have examined the effects of FVB on exhaust emission parameters. Tüccar [16] investigated the effects of Foeniculum vulgare oil biodiesel and diesel fuel added with hydroxy gas on vibration, noise and emission parameters in the diesel engine. On the other hand, any study that investigates the effects of FVB with $\mathrm{NH}_{3}$ additive has not been found according to our knowledge.

\section{Material and Method}

In this study, FVB was mixed with $\mathrm{NH}_{3}$ in different proportions to examine the effects of $\mathrm{NH}_{3}$ additive on engine emission and performance by using Diesel-RK Programme. These proportions are FVB100, FVB95A5, FVB90A10, FVB85A15 and FVB80A20. Fuel properties of $\mathrm{FVB}$ and $\mathrm{NH}_{3}$ were given in Table 1 [16].

Table 1. Fuel Properties

\begin{tabular}{lccc}
\hline \multicolumn{1}{c}{ Properties } & FVB & $\mathrm{NH}_{3}$ & $\begin{array}{c}\text { European } \\
\text { Biodiesel } \\
\text { Standard }\end{array}$ \\
\hline EN 14214)
\end{tabular}

In Diesel-RK Programme, the combustion simulations were performed according to the technical properties of the test engine in the Mechanical Engineering Laboratory of Adana Alparslan Türkeş Science and Technology University. The engine properties were given in Table 2 [16].

In this study, Mitsubishi Canter 4D31 diesel engine was simulated to analyze its performance and emission parameters by using variable RPM values. The nominal RPM value was selected as $1200 \mathrm{rev} / \mathrm{min}$ and gradually increased until 2400 $\mathrm{rev} / \mathrm{min}$.

Table 2. Technical properties of the test engine

\begin{tabular}{cc}
\hline Specifications & Description \\
\hline Brand & Mitsubishi Canter \\
Model & 4D31 \\
Configuration & In-line 4 \\
Type & Direct injection diesel \\
with glow plug \\
Displacement & $3298 \mathrm{cc}$ \\
Bore & 100 \\
Stroke & 105 \\
Power & $91 \mathrm{HP} \mathrm{@} \mathrm{3500} \mathrm{rpm}$ \\
Torque & $223 \mathrm{Nm} \mathrm{@} \mathrm{2200} \mathrm{rpm}$ \\
Oil Cooler & Water-cooled \\
\hline
\end{tabular}

In this present study, the engine performance parameters were investigated according to the specific fuel consumption $(\mathrm{kg} / \mathrm{kWh})$, engine power $(\mathrm{kW})$, torque $(\mathrm{Nm})$ and volumetric efficiency values by using Diesel-RK Programme. In addition to that oxide of nitrogen (ppm), particulate matter $(\mathrm{g} / \mathrm{kWh})$ and smoke opacity emission values were analyzed to obtain the effects of the $\mathrm{NH}_{3}$ additive on the engine emission parameters.

\section{Result and Discussion}

In this study, fennel biodiesel (FVB100) from F. Vulgare oil was used as the main fuel. Different amounts of $\mathrm{NH}_{3}(5 \%, 10 \%, 15 \%$ and $20 \%)$ were added to $\mathrm{FVB}$ and the effect of $\mathrm{NH}_{3}$ additive on engine performance and emission parameters was investigated according to the combustion simulation results by using Diesel-RK Programme.

\subsection{Engine emission parameters}

Compression-ignition engines (CI) produce more hazardous emissions according to the spark-ignition engines (SI). Korakianitis et. al [17] compared the performance and emission parameters of natural fueled SI and CI engines. Obtained results showed that SI engines can produce lower carbon dioxide $\left(\mathrm{CO}_{2}\right)$, carbon monoxide (CO) and unburned hydrocarbons (HC) according to $\mathrm{CI}$ engines. $\mathrm{NO}_{\mathrm{x}}$ and $\mathrm{PM}$ emission values are extremely critical parameters for CI engines. In addition to that, the PM parameter is directly proportional to smoke opacity. Therefore, the effect of $\mathrm{NH}_{3}$ 
additive on these parameters was evaluated according to different RPM values.

\subsubsection{Oxides of nitrogen $\left(\mathrm{NO}_{\mathrm{x}}\right)$}

Figure 1 is a plot of $\mathrm{NO}_{\mathrm{x}}$ emissions of FVB100, FVB95A5, FVB90A10, FVB85A15 and FVB80A20 fuels in different RPM values. The $\mathrm{NH}_{3}$ additive can change the physical properties, oxygen capacity and reaction temperatures of the fuel. $\mathrm{Li}$ et. al [18] numerically investigated $\mathrm{NH}_{3}$ combustion according to different $\mathrm{O}_{2}$ content. These variable parameters directly can affect the amount of $\mathrm{NO}_{x}$ formation. Moreover, the $\mathrm{NH}_{3}$ additive can reduce the $\mathrm{NO}_{\mathrm{x}}$ emission due to having a higher cetane number according to the main fuel. In this present study, as the $\mathrm{NH}_{3}$ additive in the FVB was increased, the amounts of $\mathrm{NO}_{\mathrm{x}}$ emission dramatically decreased. The lowest $\mathrm{NO}_{\mathrm{x}}$ value was observed for the FVB80A20 fuel at high rpm values due to its high $\mathrm{NH}_{3}$ content. Therefore, the optimal amount of $\mathrm{NH}_{3}$ in $\mathrm{FVB}$ was found as $20 \%$ for $\mathrm{NO}_{\mathrm{x}}$ emission. Because after this $\mathrm{NH}_{3}$ content $\left(20 \% \mathrm{NH}_{3}\right)$ in fennel biodiesel, a significant change was not observed in $\mathrm{NO}_{\mathrm{x}}$ emission. In addition to that, the maximum reduction in $\mathrm{NO}_{\mathrm{x}}$ emission was calculated as $33.45 \%$. There are several studies in the literature which also reported a $3.15 \%$ reduction in $\mathrm{NO}_{\mathrm{x}}$ emission value with 20 percent $\mathrm{NH}_{3}$ addition (R. Sivasubramaniana et. al 2019) [1]. In addition to that, $\mathrm{NO}_{\mathrm{x}}$ emissions values reduced until the $60 \% \mathrm{NH}_{3}$ content (Reiter et. al 2010) [19]. As a result of these reference studies, it was concluded that the $\mathrm{NH}_{3}$ additive in the fuel can reduce $\mathrm{NO}_{\mathrm{x}}$ emissions at a certain rate.

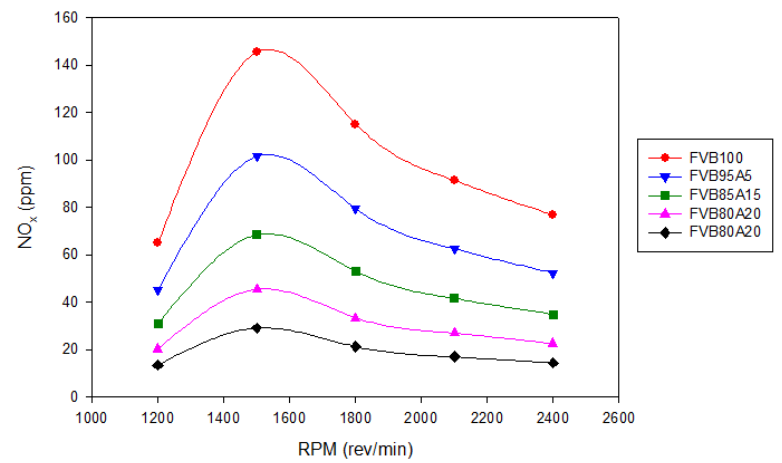

Figure 1. Oxides of Nitrogen $\left(\mathrm{NO}_{\mathrm{x}}\right)$ - Engine Speed (RPM)

\subsubsection{Particulate matter (PM)}

Figure 2 demonstrates the PM trend of FVB100, FVB95A5, FVB90A10, FVB85A15 and
FVB80A20 fuels in different RPM values. The lowest PM value was obtained for FVB100 at $1200 \mathrm{rpm}$ value due to having high oxygen content. As the $\mathrm{NH}_{3}$ additive was increased in FVB, PM values increased directly proportional. The maximum increment was calculated as $17.87 \%$. The main reason for the increment in PM emission values can be described as incomplete combustion. In addition to that, other reasons for this increment are the low burning temperature and low supply of oxygen. When PM values were compared with $\mathrm{NO}_{\mathrm{x}}$ values, a reverse correlation relation was determined between PM and $\mathrm{NO}_{\mathrm{x}}$ parameters. There are several studies that investigate PM emission values in the literature. PM emission values of $60 \% \mathrm{DME}-40 \% \mathrm{NH}_{3}$ and $40 \% \mathrm{DME}-$ $60 \% \quad \mathrm{NH}_{3}$ mixtures are slightly greater according to PM value of 100\% DME (Ryu et. al 2014) [4]. As a result, it was concluded that the $\mathrm{NH}_{3}$ additive in the fuel increased the PM emission values due to having low oxygen content, low burning temperature and incomplete combustion.

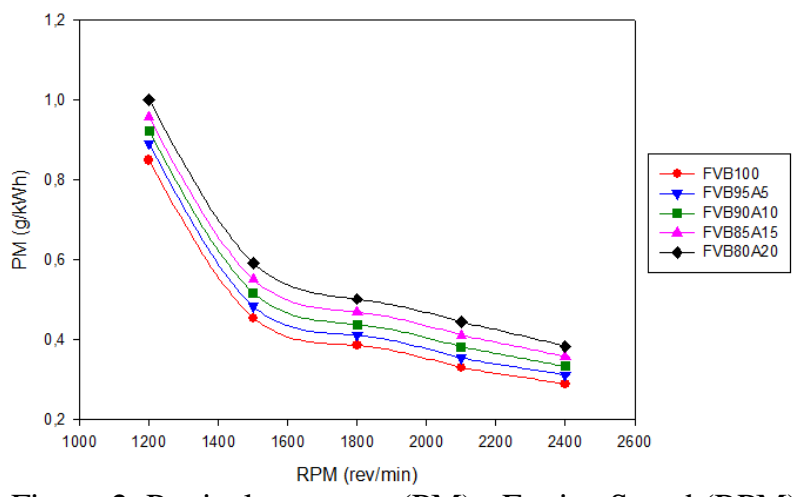

Figure 2. Particulate matter (PM) - Engine Speed (RPM)

\subsubsection{Smoke opacity}

Figure 3 shows the smoke opacity trend of FVB100, FVB95A5, FVB90A10, FVB85A15 and FVB80A20 fuels in different RPM values. As seen in the graph, the increment in the amount of ammonia adversely affected smoke opacity parameter in different RPM values. The combustion temperature in the cylinder reduced due to increasing $\mathrm{NH}_{3}$ content and therefore, the main reason for increment in smoke opacity values can be described as poor oxidation. The percentage of the maximum increment in smoke opacity value was calculated as $3.18 \%$. On the other hand, when the RPM values gradually were increased, the smoke opacity parameter regularly showed a reduction trend. The 
changing trend of the smoke opacity parameter indicates a similarity with the other studies as mentioned in PM section. Therefore, the accuracy of smoke opacity data can be compared according to PM data due to the similarity relation between smoke opacity and PM data.

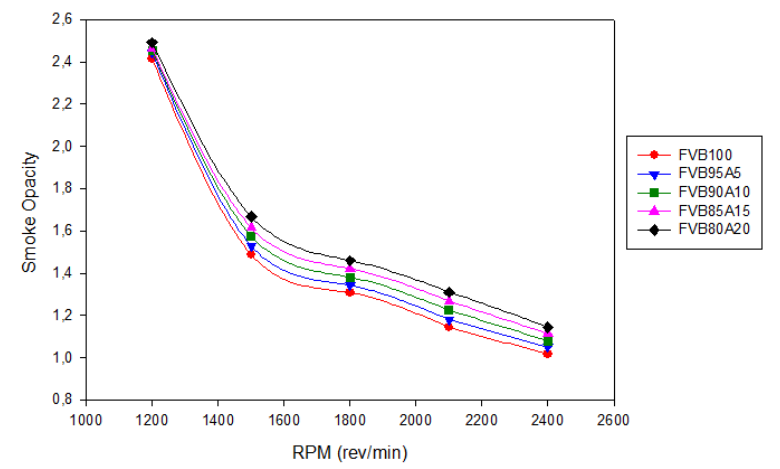

Figure 3. Smoke Opacity - Engine Speed (RPM)

\subsection{Engine performance parameters}

Fuel additives have a huge impact on engine performance. SFC, power, torque and volumetric efficiency parameters can give pieces of information about the engine performance. Therefore these parameters were investigated by using FVB100, FVB95A5, FVB90A10, FVB85A15 and FVB80A20 fuels according to different RPM values.

\subsubsection{Specific fuel consumption (SFC)}

Figure 4 shows the trend of SFC parameter of FVB100, FVB95A5, FVB90A10, FVB85A15 and FVB80A20 fuels in different RPM values. SFC basically can be defined as how efficiently the engine converts fuel into power. Therefore, SFC is known as one of the most determinant parameters in terms of engine performance. The lowest SFC value was calculated for FVB100 fuel. When the $\mathrm{NH}_{3}$ additive in FVB gradually was increased, SFC parameter showed a regular increment trend. The percentage of the maximum increment was calculated as $11.41 \%$. There are several studies in the literature which also reported the diesel fuel with $\mathrm{NH}_{3}$ additive has a higher SFC value according to $100 \%$ diesel fuel at constant and variable torque values (Lasocki et. al 2019) [20].

\subsubsection{Power}

Figure 5 demonstrates the trend of engine power parameter of FVB100, FVB95A5, FVB90A10, FVB85A15 and FVB80A20 fuels in different
RPM values. When the amount of $\mathrm{NH}_{3}$ in the FVB was increased, the engine power gradually showed a reduction. The maximum reduction was calculated as $10.05 \%$.

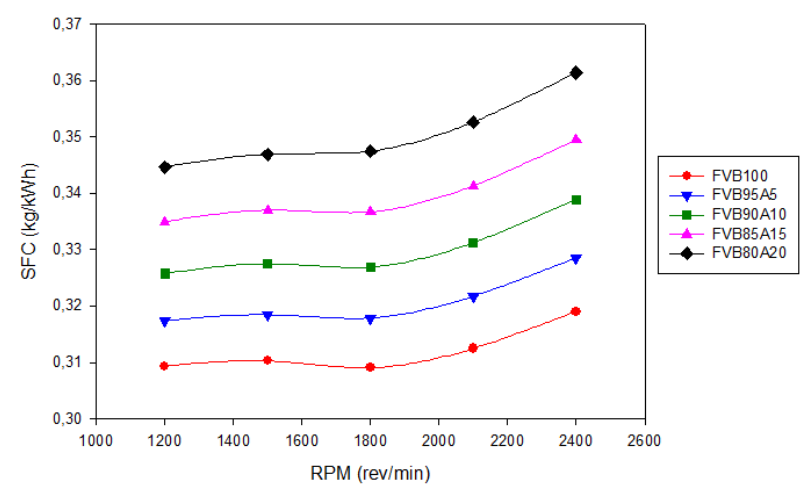

Figure 4. Specific Fuel Consumption (SFC) - Engine Speed (RPM)

There are several studies that investigate the engine power values in the literature. Dual fuel $\left(\mathrm{NH}_{3}\right.$-diesel fuel) increased the power of the engine according to diesel fuel (Reiter et. al 2011) [5]. Otherwise, high engine power was obtained for diesel fuel (baseline) but dimethyl ether (DME) - $\mathrm{NH}_{3}$ mixtures $(20 \%$ and $40 \%$ $\mathrm{NH}_{3}$ additive) has lower the engine power according to diesel fuel (Gross et. al 2013) [7]. Therefore, $\mathrm{NH}_{3}$ additive negatively affected the engine power as seen in Figure 5. At the same time, the engine power is directly related to the engine torque. This reduction in engine power negatively affected the torque trend at the same rate as seen in Figure 6.

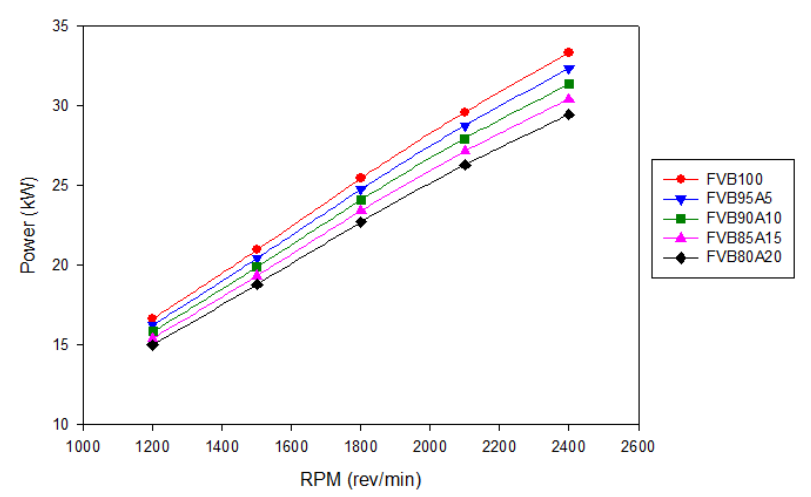

Figure 5. Power $(\mathrm{kW})$ - Engine Speed (RPM)

\subsubsection{Torque}

Figure 6 shows the trend of engine torque parameter of FVB100, FVB95A5, FVB90A10, FVB85A15 and FVB80A20 fuels in different RPM values. The torque output of the compression-ignition engine mainly depends on its combustion pressure and rate of combustion. The $\mathrm{NH}_{3}$ additive in the fuel reduced these 
parameters inside the engine cylinder. Therefore, the increment of $\mathrm{NH}_{3}$ additive in FVB caused a reduction in the engine torque as seen in Figure 6. The maximum reduction was calculated as $10.1 \%$. This reduction percentage is almost the same as the loss of engine power. There are several studies in the literature which also reported when the $\mathrm{NH}_{3}$ was added to diesel fuel, the torque of engine increased according to diesel (baseline) fuel (Reiter et. al 2010) [19].

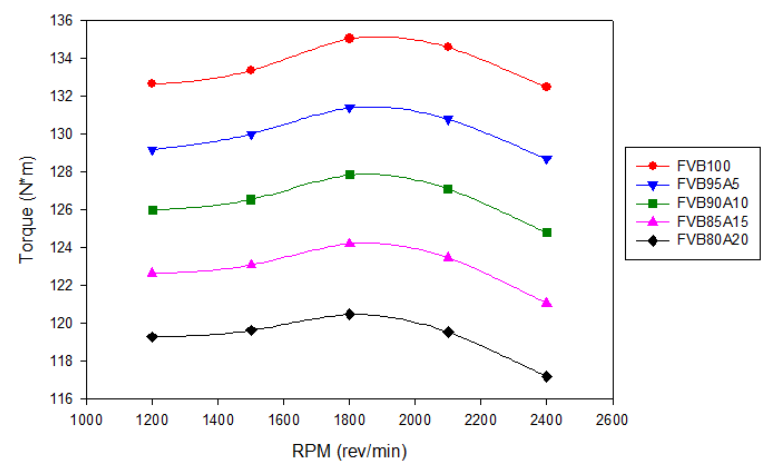

Figure 6. Engine Torque (N.m) - Engine Speed (RPM)

\subsubsection{Volumetric efficiency}

Figure 7 shows the trend of engine torque parameter of FVB100, FVB95A5, FVB90A10, FVB85A15 and FVB80A20 fuels in different RPM values. The volumetric efficiency is related to how an engine's pumping capacity is defined. $\mathrm{NH}_{3}$ additive in FVB caused to increase the volumetric efficiency of fuel mixtures. The density of the fuel is one of the most important factors affecting volumetric efficiency depending on the changing chemical properties of the fuel.

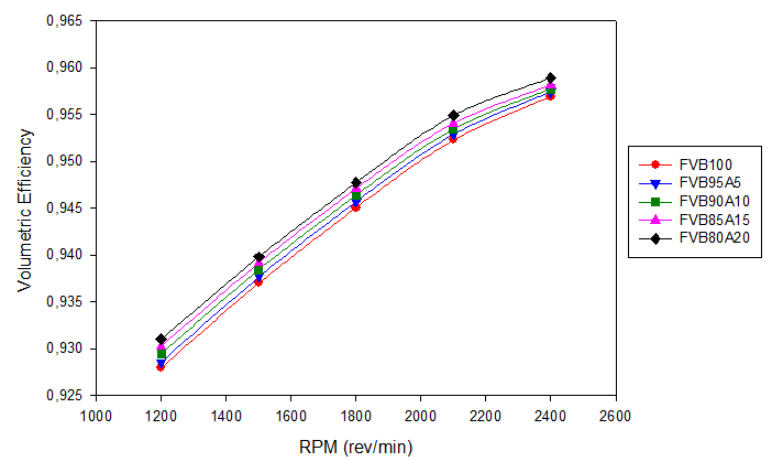

Figure 7. Volumetric Efficiency - Engine Speed (RPM)

As seen in Figure 7, when the $\mathrm{NH}_{3}$ additive gradually was increased, the volumetric efficiency increased directly proportional by $1.3 \%$. The remarkable change was not observed with relation to the simulation result but the positive effect of $\mathrm{NH}_{3}$ as a fuel additive was revealed on the volumetric efficiency parameter. This positive effect is due to changes in density as mentioned in the previous section. Therefore, as the density of FVB- $\mathrm{NH}_{3}$ mixtures decreased with relation to the amount of $\mathrm{NH}_{3}$, the increment was observed in volumetric efficiency. As a result of the literature study, there are not many studies that investigate the volumetric efficiency. Therefore, this parameter has a critical importance for the originality of the study.

\section{Conclusion}

The effects of $\mathrm{NH}_{3}$ additive in $\mathrm{FVB}$ on engine performance and engine emission parameters were investigated at different engine speeds by using Diesel-RK programme. Combustion simulations of FVB - $\mathrm{NH}_{3}$ mixtures were simulated in accordance with the technical properties of the test engine (Mitsubishi Canter 4D31). The amount of $\mathrm{NH}_{3}$ additive was fractionally increased from $5 \%$ to $20 \%$ percent to observe the changes in engine performance and emission parameters. These mixtures are FVB100, FVB95A5, FVB90A10, FVB85A15 and FVB80A20. As a result, the following conclusions can be drawn from these combustion simulations;

- According to the combustion simulations, the use of $\mathrm{NH}_{3}$ as a fuel additive significantly reduced $\mathrm{NO}_{\mathrm{x}}$ emissions. The maximum reduction was calculated as $33.45 \%$. The largest decrease was observed in $5 \% \mathrm{NH}_{3}$ additive for $\mathrm{NO}_{\mathrm{x}}$ emissions. This decline ratio gradually decreased from $5 \%$ until $20 \% \mathrm{NH}_{3}$ additive. In addition to that, there was no noticeable change in $\mathrm{NO}_{x}$ emissions after $20 \% \mathrm{NH}_{3}$ additive. When combustion simulation data were compared with the results of previous studies in the literature, the decreasing effect of $\mathrm{NH}_{3}$ additive on $\mathrm{NO}_{\mathrm{x}}$ emission parameter was validated in the scope of this study.

On the other hand, a reverse relationship was obtained between $\mathrm{PM}$ and $\mathrm{NO}_{\mathrm{x}}$ emission parameters. PM values increased by maximum $17.87 \%$ as a result of increasing the $\mathrm{NH}_{3}$ additives in fennel biodiesel. The main reasons for this increment can be described as incomplete combustion and low oxygen content depending on the amount of $\mathrm{NH}_{3}$ additive in the mixtures. As revealed in previous studies in the literature, $\mathrm{NH}_{3}$ additive negatively affected $\mathrm{PM}$ parameter on the contrary of $\mathrm{NO}_{\mathrm{x}}$ parameter.

The smoke opacity parameter has critical 
importance due to being a new parameter among other emission parameters in literature. When smoke opacity values were compared with PM values, it was observed that both of them had a similar graphic trend. $\mathrm{NH}_{3}$ additive caused the increment of smoke opacity relative to additive ratio. Smoke opacity parameter showed a maximum of $3.18 \%$ increment. On the other hand, lower smoke opacity values were observed at high engine speeds.

- $\mathrm{NH}_{3}$ additive negatively affected the SFC parameter similar to the results of previous studies in the literature. As the amount of $\mathrm{NH}_{3}$ additive was increased, SFC parameter showed an increment trend. The percentage of the maximum increment is $11.41 \%$ in SFC parameter. In addition to that, the highest SFC value was obtained for FVB80A20 fuel mixture. The effect of $\mathrm{NH}_{3}$ additive on the SFC parameter can be interpreted more clearly and understandably with the power and torque parameters. Engine power and torque reduced due to increasing the $\mathrm{NH}_{3}$ additive in FVB and both of them approximately showed the same downward trend. The engine power and torque respectively showed the maximum $10.05 \%$ and $10.1 \%$ reduction due to the increment of SFC parameter. Volumetric efficiency is a determinant factor to reveal the effects of $\mathrm{NH}_{3}$ additive among other engine performance parameters. Volumetric efficiency showed directly proportional alteration with engine speed. In addition to that, the $\mathrm{NH}_{3}$ additive in FVB positively increased the volumetric efficiency of the engine. This increment was calculated as $1.3 \%$.

As a result, the result of the combustion simulations in $\mathrm{FVB}-\mathrm{NH}_{3}$ mixtures was compared and interpreted according to the result of the previous studies in the literature. In the scope of this study, it was determined that $\mathrm{NH}_{3}$ additive significantly reduced emission parameters $\left(\mathrm{NO}_{\mathrm{x}}\right)$ except the PM parameter. In addition to that, it has been observed that the $\mathrm{NH}_{3}$ additive does not generally have a positive effect on the engine performance except volumetric efficiency as it does on the emission parameters.

\section{Abbreviations}

FVB : Foeniculum vulgare oil biodiesel

PM : Particulate matter
SFC : Specific fuel consumption

DME : Dimethyl ether

BSCO : Brake specific carbon monoxide

BSHC : Brake specific hydrocarbon

$\mathrm{NH}_{3}$ : Ammonia

$\mathrm{CO}$ : Carbon monoxide

$\mathrm{CO}_{2}$ : Carbon dioxide

$\mathrm{HC}$ : Hydrocarbon

CI : Compression- ignition engine

SI : Spark-ignition engine

RPM : Revolutions per minute

HP : Horsepower

\section{References}

1. Fernando, Sandun, Chris Hall, and Saroj Jha., "NO${ }_{x}$ reduction from biodiesel fuels, Energy \& Fuels", Volume 20, Issue 1, pp. 376382, 2006.

2. Sivasubramanian, R., J. B. Sajin, and Gokul Omanakuttan Pillai., "Effect of ammonia to reduce emission from biodiesel fuelled diesel engine", International Journal of Ambient Energy, pp. 1-5, 2019.

3. Şahin, Zehra, İmdat Ziya Akcanca, and Orhan Durgun., "Experimental investigation of the effects of ammonia solution $\left(\mathrm{NH}_{3} \mathrm{OH}\right)$ on engine performance and exhaust emissions of a small diesel engine", Fuel, Volume 214, pp. 330-341, 2018.

4. Ryu, Kyunghyun, George E. ZacharakisJutz, and Song-Charng Kong., "Performance characteristics of compression-ignition engine using high concentration of ammonia mixed with dimethyl ether", Applied Energy, Volume 113, pp. 488-499, 2014.

5. Reiter, Aaron J., and Song-Charng Kong., "Combustion and emissions characteristics of compression-ignition engine using dual ammonia-diesel fuel", Fuel, Volume 90, Issue 1, pp. 87-97, 2011.

6. Ryu, Kyunghyun, George E. ZacharakisJutz, and Song-Charng Kong., "Effects of gaseous ammonia direct injection on performance characteristics of a spark-ignition engine", Applied energy, Volume 116, pp. 206215, 2014.

7. Gross, Christopher W., and SongCharng Kong., "Performance characteristics of a compression-ignition engine using directinjection ammonia-DME mixtures", Fuel, Volume 103, pp. 1069-1079, 2013.

8. Yeh, An Chin, and Hsunling Bai., 
"Comparison of ammonia and monoethanolamine solvents to reduce $\mathrm{CO} 2$ greenhouse gas emissions", Science of the Total Environment, Volume 228, Issue 2-3, pp. 121133, 1999.

9. Rehbein, M. C., et al., "Mixtures of ammonia and organic solvents as alternative fuel for internal combustion engines", Energy \& Fuels, Volume 33, Issue 10, pp. 10331-10342, 2019.

10. Pyrc, Michał, et al., "An experimental investigation of the performance, emission and combustion stability of compression ignition engine powered by diesel and ammonia solution $\left(\mathrm{NH}_{4} \mathrm{OH}\right) "$, International Journal of Engine Research, Volume 22, Issue 8, pp. 2639-2653, 2021.

11. Badgujar, Shamkant B., Vainav V. Patel, and Atmaram H. Bandivdekar., "Foeniculum vulgare Mill: a review of its botany, phytochemistry, pharmacology, contemporary application, and toxicology", BioMed research international, 2014.

12. Moura, Lucinewton S., et al., "Supercritical fluid extraction from fennel (Foeniculum vulgare): global yield, composition and kinetic data", The Journal of supercritical fluids, Volume 35, Issue 3, pp. 212-219, 2005.

13. Falzari, Linda M., Robert C. Menary, and Valerie A. Dragar., "Optimum stand density for maximum essential oil yield in commercial fennel crops", HortScience, Volume 41, Issue 3, pp. 646-650, 2006.

14. Al_Dawody, Mohamed F., and S. K. Bhatti., "Experimental and computational investigations for combustion, performance and emission parameters of a diesel engine fueled with soybean biodiesel-diesel blends", Energy Procedia, Volume 52, pp. 421-430, 2014.

15. Datta, Ambarish, and Bijan Kumar Mandal., "Numerical investigation of the performance and emission parameters of a diesel engine fuelled with diesel-biodieselmethanol blends", Journal of Mechanical Science and Technology, Volume 30, Issue 4, pp. 1923-1929, 2006.

16. Tüccar, Gökhan., "Effect of hydroxy gas enrichment on vibration, noise and combustion characteristics of a diesel engine fueled with Foeniculum vulgare oil biodiesel and diesel fuel", Energy Sources, Part A: Recovery,
Utilization, and Environmental Effects, Volume 40, Issue 10, pp. 1257-1265, 2018.

17. Korakianitis, T., A. M. Namasivayam, and R. J. Crookes., "Natural-gas fueled sparkignition (SI) and compression-ignition (CI) engine performance and emissions", Progress in energy and combustion science, Volume 37, Issue 1, pp. 89-112, 2011.

18. Li, Jun, et al., "Numerical study on effect of oxygen content in combustion air on ammonia combustion", Energy, Volume 93, pp. 2053-2068, 2015.

19. Reiter, Aaron J., and Song-Charng Kong., "Diesel engine operation using ammonia as a carbon-free fuel", Internal Combustion Engine Division Fall Technical Conference, Volume 49446, 2010.

20. Lasocki, J., M. Bednarski, and M. Sikora., "Simulation of ammonia combustion in dual-fuel compression-ignition engine", IOP Conference Series: Earth and Environmental Science, Volume 214, No 1, pp. 012081, 2019. 